\title{
A escola rural na produção acadêmica portuguesa: Apontamentos sobre a (in)visibilidade de um objeto de estudo
}

\author{
Renilton Cruzi
}

Universidade Federal do Pará, Brasil

\begin{abstract}
Resumo
O artigo discute a invisibilidade da escola rural na universidade portuguesa. Embora exista produção científica centrada no rural e suas relações socioculturais, onde se foca, direta ou indiretamente, a escola, desde os anos de 1980, com Pinto (1985), passando por Stoer e Araújo (1992) e Canário (1995), até chegar ao final dos anos de 1990, com Sarmento, Sousa, e Ferreira (1998), a produção acadêmica disposta a problematizar a escola rural não ocorreu à altura da importância social, cultural e econômica daquele espaço. A pesquisa ocorre através de um estudo bibliográfico em dez revistas científicas direcionadas à educação, e do levantamento das teses e dissertações produzidas nas principais universidades portuguesas. Os dados sugerem uma crescente invisibilidade da escola rural na produção acadêmica e nas publicações especializadas em educação em Portugal, bem como a inexistência de força social atrelada aos interesses dos sujeitos do meio rural capaz de voltar a universidade à escola rural.
\end{abstract}

Palavras-chave

Escola rural; Invisibilidade; Produção acadêmica

\section{Introdução}

Ainda distante das prioridades de desenvolvimento, o mundo rural português assiste nas últimas décadas um intenso movimento de sua 
população na direção do estrangeiro e dos centros urbanos nacionais, provocando uma autêntica "sangria humana" nas aldeias (Nascimento, 2008). Iniciativas endógenas, entretanto, têm procurado inventar ou reinventar o rural tradicional de matriz camponesa, apostando intensamente na divulgação dos produtos locais, na dinamização do turismo e da segunda residência, de modo a incorporar a identidade e os valores que marcam o território na estratégia de desenvolvimento local (Silva \& Marques, 2013).

Os números oficiais referentes aos territórios rurais dão a dimensão de sua importância socioeconômica ao mesmo tempo em que revelam desafios e constrangimentos que lhes marcam o presente e condicionam o futuro. Apesar de o Instituto Nacional de Estatística - INE não mais usar o rural como nível geográfico no Censo Populacional de 2011, tendo neste levantamento utilizado a categoria lugar $^{1}$ como espaço de referência, é possível verificar em documentos governamentais como o 'Plano de Desenvolvimento Rural 2020' a indicação de que nas zonas rurais de Portugal continental vive $33,3 \%$ de sua população, estando esta espalhada por $81,4 \%$ de sua superfície (Ministério da Agricultura e do Mar, 2014). Em 2011, segundo o INE, mais de 4 milhões de pessoas viviam em lugares com menos de 2000 habitantes, sendo que em 174 municípios portugueses $(56,48 \%)$ a totalidade da população vivia nesses lugares (INE, 2015).

As explorações agrícolas ainda ocupam metade da área geográfica do país e $80 \%$ do volume de trabalho agrícola é realizado pela mão-de-obra familiar. Entretanto, é nítida a dificuldade experimentada no âmbito da atividade agrícola quando se põe em relevo o produtor-tipo: este é homem, tem 63 anos, apenas completou o $1^{\circ}$ ciclo do ensino básico, tem formação agrícola exclusivamente prática e trabalha nas atividades agrícolas da exploração cerca de 22 horas por semana; o seu agregado familiar é constituído por 3 indivíduos e o rendimento provém maioritariamente de pensões e reformas (Portugal - PDR 2020) (Ministério da Agricultura e do Mar, 2014).

Apesar de não mais possuir a importância econômica que exibia no passado, a produção agropecuária ainda é o cimento que liga os diversos elementos que constituem a identidade do mundo rural português. Entretanto, outras atividades econômicas ganham espaço no meio rural e impõem novas dinâmicas e uma nova estetização (Covas \& Covas, 2013) que tornam ainda 
mais complexas as estratégias de desenvolvimento e incontornáveis as ações voltadas à valorização do potencial humano, sejam dentro ou fora das instituições formais de ensino.

Neste campo, verifica-se que as políticas do Estado têm optado pelo encerramento de várias escolas rurais, nomeadamente as de $1^{\circ}$ ciclo, cujas pequenas dimensões e alegada precariedade pedagógica surgem como justificativas para ações administrativas voltadas à racionalização da oferta educativa à população do campo (Palmeiro, 2011). Também por esse motivo, a escola rural adentra ao século XXI a ver diminuída, ou mesmo negada, pelas políticas públicas, sua legitimidade social e pedagógica, mas também se depara com a academia quase de olhos fechados aos seus principais desafios. Ainda que sem poder de mobilização alargada, há, no sentido contrário, um movimento voltado à afirmação e à valorização da escola em meio rural protagonizado, quase sempre, por organizações da sociedade civil que percebem naquela instituição, além de um potencial laboratório pedagógico (Calvi, 1995; Collot, 1994), uma importante aliada na construção de soluções aos dilemas do desenvolvimento rural (Oliveira, 2005; Amiguinho, 2003a, 2005; Canário, 2000; Silva, 2010).

É objetivo deste texto colaborar com esse debate ao expor e discutir, mesmo que panoramicamente, alguns dados $^{2}$ concernentes a produção acadêmica portuguesa voltada à problemática da escola rural.

\section{A escola rural em Portugal}

Em relação às significativas alterações econômicas, geográficas e culturais vivenciadas pelo meio rural nas últimas décadas, Portugal segue o mesmo percurso trilhado noutros cantos da Europa e do mundo. As razões destas mudanças também não distam daquelas que traçaram um novo contorno e estabeleceram novas funções aos espaços rurais na Europa (Calvário, 2010). O padrão de desenvolvimento baseado no crescimento econômico e com base na indústria e no espaço urbano, há muito estabelecido no país e reforçado nas últimas décadas, contribuiu para debilitar a agricultura nacional, impôs um êxodo rural de larga extensão, tanto para os centros urbanos nacionais como para o estrangeiro, e, em muitos casos, transformou o espaço rural em local de residência e não de trabalho. 
Também como noutros cantos da Europa (Souza, 2011), em Portugal a escola rural sofreu e sofre os efeitos das decisões políticas e econômicas que sentenciam a falência ou, no melhor dos casos, a secundarização do meio rural. Tais decisões ignoram ou desconsideram o fato de que o problema da escola instalada naquele espaço precisa ser analisado, essencialmente, como um aspecto parcelar do "colapso" do mundo rural, impelido por um tipo de desenvolvimento basicamente focado no crescimento econômico (Yves, 1995).

Nos anos de 1990, Amiguinho (1995) já alertava para o fato de que as robustas transformações socioeconômicas verificadas no meio rural trouxeram consequências diretas ao funcionamento da escola. Dizia o autor que, ao não delimitar a questão da escola no contexto de degradação e subordinação pelo qual o meio rural vem passando há muito tempo, as políticas do Estado têm utilizado justamente a situação de isolamento de alunos e professores para encerrar as atividades de muitas delas. E assim, como resultado dessa "voragem de punição das vítimas, a aldeia acaba por perder um dos últimos sinais do reconhecimento da sua existência e da sua identidade como espaço social" (Amiguinho, 1995, p. 114), o que só aprofunda o já alargado processo de desertificação humana dos campos.

É possível ver, entretanto, na contramão de ações estatais que tendem a decretar a perda de importância, a inviabilidade econômica ou a limitação pedagógica das escolas do meio rural, especialmente as de pequenas dimensões, algumas iniciativas comunitárias e autárquicas que, com maior ou menor abrangência, têm procurado resgatar a importância e demonstrar as possibilidades pedagógicas e culturais da escola rural, enxergando-a como uma indispensável aliada no processo de revitalização do espaço rural.

Além de várias petições virtuais que podem ser encontradas na web manifestando descontentamento com o processo de encerramento de escolas e freguesias rurais, mobilizações em nível local ocorrem em municípios portugueses há alguns anos, onde autarquias, diversas associações culturais e desportivas, encarregados de educação e estudantes juntam-se para defender a importância e a permanência da escola rural. Destaca-se, entretanto, o trabalho do Instituto das Comunidades Educativas - ICE ${ }^{3}$, que há vários anos desenvolve ações no terreno e contribui para o debate que envolve a educação em meio rural em Portugal. 
O tema da educação das populações rurais esteve sempre em relevo no ICE, não apenas em suas ações interventivas, onde se destaca o Projeto Escolas Rurais, mas também em diversas publicações periódicas ou esporádicas que relatam e analisam experiências desenvolvidas por suas equipes de trabalho ou por pesquisadores externos, portugueses ou estrangeiros, que destacam as possibilidade e limitações da escola rural diante do atual quadro em que se encontra o campo português e europeu.

Embora a centralização do foco das ações no desenvolvimento local possa ser um limitador da capacidade emancipatória dos projetos do ICE, uma vez que o enfrentamento dos problemas vivenciados no campo, dentre eles o da escola, passa por uma compreensão alargada de suas causas e por uma ação abrangente, que considere múltiplas frentes de batalha, haja vista a impossibilidade de uma emancipação de caráter parcial (Vendramini, 2005), as experiências educativas postas em prática pelo instituto, têm, certamente, um potencial emancipatório, pois nele encontra-se consolidada "a ideia do rural e da educação em meio rural como uma forma de resistência à mercadorização e urbanização, que é dominante por efeito da globalização social, sendo sustentada, em contrapartida, uma concepção que é promotora da educação ao serviço do desenvolvimento" (Sarmento \& Oliveira, 2005, p. 95).

Mesmo a presenciar um contínuo e preocupante declínio populacional dos espaços rurais, o encerramento de escolas e a consequente perda de vínculo cultural dos mais jovens com seus locais de origem, e a dispor de instituições da sociedade civil do porte do ICE, onde atuam intelectuais reconhecidos nacional e internacionalmente, o tema da educação em meio rural em Portugal ainda não estimula um vigoroso debate acadêmico. Como será possível ver a seguir, a produção acadêmica nos cursos de mestrado e doutoramento das universidades portuguesas, assim como as publicações em revistas científicas na área das Ciências da Educação, focam timidamente a educação em meio rural.

\section{A produção acadêmica recente sobre a educação rural em Portugal}

A pesquisa acadêmica sobre a educação em Portugal é relativamente recente, tendo de fato avançado somente a seguir ao fim do regime 
salazarista, em meados dos anos de 1970 (Correia \& Stoer, 1995), e ganhado maior envergadura na década de 1980, altura em que foram criados diversos cursos de mestrado e doutorado no país (Campos, 1995). A necessidade de, com alguma pressa, formar em serviço os profissionais do ensino seria uma das causas mais visíveis do retardamento a que foi submetida a pesquisa no campo das Ciências da Educação em Portugal (Correia \& Stoer, 1995). As primeiras décadas que seguem o fim do Estado Novo foram dedicadas à qualificação dos profissionais docentes que já atuavam ou viriam a atuar no ensino superior, numa clara movimentação que visava fortalecer a sua musculatura e garantir a qualidade necessária para realizar um movimento e uma expansão para o exterior.

Em Tradição e Mudança na Escola Rural, Sarmento, Sousa, e Ferreira (1998) reconheciam que "as escolas rurais são, entre nós, um não-assunto na agenda investigativa, salvo as excepções, aliás recentes (...)" (p. 15). Os pesquisadores que compunham as exceções destacadas pelos autores constituem um pequeno grupo de estudiosos que a partir de meados dos anos de 1980 se dedicam (ou se dedicaram), direta ou indiretamente, à problemática que envolve a educação das populações rurais.

A educação em meio rural aparece no clássico trabalho de José Madureira Pinto (1985), Estruturas Sociais e Práticas Simbólico-Ideológicas nos Campos: Elementos de teoria e de pesquisa empírica, que, apesar de não centrar sua abordagem exclusivamente na educação em meio rural, traz uma valiosa seção voltada ao tema que em muito contribui para a compreensão dos elementos que envolvem a cultura camponesa e a educação escolar. $O$ autor defende a tese de que a escola favorece a passagem dos filhos dos trabalhadores rurais à condição de proletários, uma vez que, ao levar a cultura urbana ao meio rural, a escola cria as condições para o desenvolvimento dos elementos culturais necessários à criação da relação salarial que sustenta a produção capitalista. Dada a sua clareza analítica, o texto de Madureira Pinto passa a ser uma referência incontornável para os estudos sobre a escola rural produzidos posteriormente.

No início dos anos noventa surgem em Portugal duas obras que também serão tornadas clássicas no debate a propósito da educação escolar rural, uma vez que suas contribuições para o desvelamento da relação travada entre a escola e a cultura local terão forte impacto na produção de 
estudos nos anos seguintes. Em 1990, Raul Iturra demonstra, em Fugirás à escola para trabalhar a terra, que há um forte choque cultural entre os saberes dominantes, disseminados pela escola, e os saberes populares oralmente manifestados pelas crianças do meio rural. Para Iturra (1990), o insucesso na trajetória escolar aparece como uma das principais consequências dessa imposição cultural. Dois anos depois, Stephen Stoer e Helena Araújo (1992) publicam Escola e Aprendizagem para o Trabalho num País da (semi)periferia europeia, onde abordam a educação em meio rural como aprendizagem para o trabalho. Os autores buscam "investigar o choque potencial entre a expansão da escola urbana (escolarização de massas) e a cultura rural, no processo que conduz à integração do campesinato na relação salarial" (Stoer \& Araújo, 1992, p. 21). Uma de suas conclusões é a de que, no Portugal semirural, a aprendizagem para o trabalho "parece significar, sobretudo, aprender a sobreviver numa economia clandestina ou aprender a viver com a frustração de um sonho nunca realizado" (Stoer \& Araújo, 1992, p. 103).

Ao longo dos anos noventa outros estudos importantes foram realizados e publicados, fruto de investigações empíricas desenvolvidas no âmbito da formação pós-graduada ou de reflexões sobre experiências em projetos de intervenção educativa condensadas em artigos, com destaque para os trabalhos de Amiguinho, Canário, e D’Espiney (1994) e de Canário (1995), que, sem negligenciar a questão da rede escolar, afirmam que a problemática da escola rural não se reduz à gestão ou à administração, pois essas dimensões da questão devem ser colocadas no interior da complexidade que envolve o desenvolvimento rural. Para os autores, a crise da escola reflete a crise do modelo de desenvolvimento imposto ao meio rural nas últimas décadas. Também merece relevo o trabalho de Formosinho (1998) que, no sentido contrário ao dos autores citados acima, discute a crise da escola rural no seio do problema da rede escolar, onde a solução passa pelo incremento de ações administrativas e organizacionais. No final da década de 1990 surge o trabalho de Sarmento et al. (1998), ao qual nos referimos no início dessa seção.

Não foram muitos os estudos que abordaram a questão da educação/escola rural em Portugal desde meados dos anos oitenta, muito embora possa haver trabalhos em outras áreas das Ciências Humanas que de forma mais indireta toquem nessa questão. O fato é que o debate chega 
aos anos 2000 ainda restrito a um pequeno grupo de pesquisadores, boa parte dos quais ligados ao ICE. Aliás, vale ressaltar que o ICE foi responsável por importantes publicações no campo da educação em meio rural nos anos de 1990, destacando-se os Cadernos ICE.

Mais de uma década e meia depois de constatado por Sarmento et al. (1998) que a escola rural é praticamente invisível aos olhos da academia em Portugal, procedemos a uma rápida exploração na produção acadêmica sobre esta temática no período de 1999 a 2014. Para tanto, consultamos a base de dados do Repositório Científico de Acesso Aberto de Portugal - RCAAP ${ }^{4}$ com o objetivo de verificarmos dentre as dissertações de mestrado e as teses de doutoramento concluídas nas instituições de ensino superior do país no referido intervalo de tempo, na área de Ciências da Educação, quantas abordavam a questão da educação/escola rural em Portugal, bem como analisamos dez das mais importantes revistas científicas ${ }^{5}$ do campo educacional editadas no país, com o fim de levantarmos a quantidade de artigos dedicados ao tema da educação/escola rural nos últimos anos.

Mesmo tendo claro os limites que as fontes escolhidas contêm para a explicitação do conjunto da produção acadêmica sobre o nosso objeto de estudo, acreditamos que os dados a seguir apresentados podem servir para reflexões acerca do envolvimento da academia com a especificidade da problemática educativa dos sujeitos sociais que habitam os espaços rurais portugueses.

Os dados foram recolhidos a partir da introdução, na página de busca do RCAAP, dos termos 'educação' e/ou 'escola' nos campos do título e/ou do assunto do trabalho. O resultado apontou para a existência de 5.464 dissertações de mestrado e 512 teses de doutoramento defendidas entre 2000 e 2014 ligadas a área das Ciências da Educação. Posteriormente, associou-se os termos 'educação'/'escola' com o termo 'rural' nos referidos campos, resultando na visualização de 54 dissertações e 3 teses onde é discutida, direta ou indiretamente, a problemática da educação/escola rural no contexto português, como pode ser visto na tabela 1. Por fim, procedeu-se a leitura dos resumos disponíveis para confirmar a real ligação do trabalho com o tema em questão.

O levantamento mostra que nos últimos quinze anos apenas $0,98 \%$ dos trabalhos acadêmicos em nível de mestrado e 0,58\% em nível de 
doutoramento no campo das Ciências da Educação lançaram o olhar à situação da educação ou da escola instalada no meio rural português. A Universidade do Minho, com 11 dissertações e 2 teses, e a Universidade do Porto, com 6 dissertações, foram as instituições onde mais produções acadêmicas voltadas à educação/escola rural foram defendidas no período.

\begin{tabular}{l|c|c}
\hline \multicolumn{1}{c|}{ Instituição } & $\begin{array}{c}\text { No de } \\
\text { dissertações }\end{array}$ & $\mathbf{N}^{\circ}$ de teses \\
\hline Universidade do Minho & 11 & 2 \\
\hline Universidade do Porto & 6 & 0 \\
\hline Universidade Portucalense & 5 & 0 \\
\hline Universidade de Lisboa & 5 & 1 \\
\hline Universidade da Madeira & 3 & 0 \\
\hline Universidade Aberta & 3 & 0 \\
\hline Instituto Superior de Psicologia Aplicada & 3 & 0 \\
\hline UTAD & 2 & 0 \\
\hline Universidade Lusófona de Humanidades e Tecnologias & 2 & 0 \\
\hline Universidade de Coimbra & 2 & 0 \\
\hline Universidade de Aveiro & 2 & 0 \\
\hline Universidade Católica Portuguesa & 2 & 0 \\
\hline Instituto Politécnico de Portalegre & 2 & 0 \\
\hline Universidade Nova de Lisboa & 1 & 0 \\
\hline Universidade do Algarve & 1 & 0 \\
\hline Universidade da Beira Interior & 1 & 0 \\
\hline Instituto Politécnico de Lisboa & 1 & 0 \\
\hline Instituto Politécnico de Bragança & 1 & 0 \\
\hline Escola Superior de Educação de Lisboa & 1 & 0 \\
\hline & 2 & 0 \\
\hline
\end{tabular}

Tabela 1 - $\mathrm{N}^{\circ}$ de teses e dissertações defendidas em universidades portuguesas sobre educação/escola rural em Portugal (2000 a 2014)

Embora as instituições de ensino ainda não tenham inserido no RCAAP a totalidade das informações referentes aos trabalhos acadêmicos defendidos no período aqui abordado, uma vez que é relativamente recente a exigência legal que as obriga a assim proceder, é possível verificar que o meio rural e seus desafios educativos são insuficientemente abordados nos trabalhos da pós-graduação em Portugal.

Essa quase invisibilidade da educação e da escola rural no âmbito dos cursos de pós-graduação stricto sensu também pode ser percebida em uma 
rápida pesquisa nos planos de ensino dos cursos de licenciatura em Educação das principais universidades do país, cuja ausência de unidades curriculares a apontar claramente a um debate mais específico sobre a realidade educativa dos habitantes do meio rural é transparente. Embora a maioria dos cursos possuam unidades curriculares focadas na Intervenção Comunitária e Desenvolvimento Local, na Animação Socioeducativa, na Educação e Multiculturalidade, a presença de referência bibliográfica obrigatória ou sugerida ligada à educação ou escola do meio rural é profundamente escassa. Talvez na frágil exposição do problema nos cursos de formação inicial dos docentes resida um dos fatores que explicam a ainda pequena produção de investigações nos ciclos de estudos posteriores.

Entretanto, a ausência ou a secundarização do debate sobre a educação das populações rurais nos cursos de formação docente e na pósgraduação também podem refletir na forma como o desenvolvimento do meio rural é percebido, tanto por atores internos àquele ambiente como pelos que, externamente, definem as políticas públicas que ali são desenvolvidas. A forma e o conteúdo da ação escolar realizada no meio rural interfere, direta ou indiretamente, na representação que os sujeitos constroem sobre si e o território em que habitam, mas também coloca em relevo o modelo de desenvolvimento no qual ela se encontra inserido.

Ao discutir o envolvimento da escola na aprendizagem para o trabalho em Portugal, Stoer e Araújo (1992) chamam a atenção para a contribuição da escolarização ao processo de "mutação simbólica" vivenciado pelos grupos camponeses. Argumentam que através da expansão da escola para o campo se garante "uma importante pré-condição material da reprodução capitalista", uma vez que haverá a possibilidade da estruturação de um exército de reserva para atender a indústria ou o setor de serviços. Após a "invasão" da escola urbana no campo, tende a ocorrer uma alteração dos "mecanismos de reprodução social, através da criação de uma mobilidade social na base do acesso ao salariato" como consequência "da posição obtida por um determinado número de anos de escolarização, certificado pelo diploma da escola" (Stoer \& Araújo, 1992, p. 18).

Canário (1997), todavia, ressalta que, por haver um défice significativo de escolarização entre a população rural, parece ser coerente que haja um esforço e um investimento na expansão da oferta educativa escolar em todos 
os níveis, uma vez que isso pode contribuir para o desenvolvimento regional e local. Porém, para o autor, o desenvolvimento educativo em meio rural não deve, necessariamente, estar atrelado a expansão linear de oferta escolar, uma vez que a simples ampliação do número de escolas tende, especialmente, a favorecer o "crescimento do mercado educativo e da massa de 'consumidores' de escola, reforçando uma lógica desenvolvimentista que, precisamente, está na raiz da crise do mundo rural" (Canário, 1997, p. 5). Por isso, conclui que as políticas públicas direcionadas ao meio rural devem integrar a oferta escolar com ações voltadas ao desenvolvimento regional e local.

É nesse sentido da integração com as ações de desenvolvimento local que Melo (1994) pensa a participação da escola nos projetos que buscam colaborar com as comunidades rurais na superação de seus entraves econômicos e sociais. Para esse autor, todas as escolas devem ser mobilizadas no trabalho educativo que acompanha o desenvolvimento rural, tanto desenvolvendo atividades curriculares como extracurriculares vinculadas às questões pertinentes à comunidade. Nesse contexto, e tendo em conta que no meio rural em crise o "espírito de iniciativa" é um elemento fundamental, a escola "deveria adoptar programas específicos, baseados em acontecimentos ocasionais e em projetos a longo prazo, a fim de apoiar e revitalizar o tecido social local e de promover nos jovens e nas crianças o hábito de pensarem e de agirem em termos de projetos planejados" (Melo, 1994, p. 148)

Amiguinho (2005), ao refletir sobre a escola e o desenvolvimento local, constata que, em meio rural, muitas vezes aquela instituição é "o serviço que resta depois de todos os outros terem desaparecido ou sido suprimidos pelo Estado" (p. 15). Tal situação, segundo o autor, longe de se configurar em fato isolado, encontra-se totalmente vinculada aos problemas mais gerais vivenciados no meio rural. O relacionamento da escola com a comunidade, em que, pese sua capacidade para contribuir para o desenvolvimento local e, ao mesmo tempo, beneficiar-se desse processo, não tem vindo a ocorrer com essa dimensão, uma vez que tem havido "dificuldades para superar perspectivas mais estritas de contextualização do currículo", bem como para "ousar no pôr à prova da velha gramática escolar" (Amiguinho, 2005, p. 16). 
Todavia, Amiguinho (2005) destaca a importância da escola na construção de processos alternativos e participativos de desenvolvimento em meio rural, nomeadamente nas redes funcionais estabelecidas com outras instituições, uma vez que é nessas redes, cuja função é fundamental para o desenvolvimento, "que a escola joga a sua importância como organização", atuando como "uma espécie de polarizadora ou nó da rede" (pp. 17-18). Garantindo a articulação entre os atores envolvidos no processo, a escola estaria afirmando a relevância no contexto local e fortalecendo as ações de desenvolvimento.

Contudo, desprovida de um debate acadêmico que a perceba como protagonista no cenário rural, a escola pouco irá contribuir com os que, endógena ou exogenamente, enfrentam a crise que há muito atinge aquele território. Nesse sentido, uma amostra do distanciamento da academia da discussão que abrange a escola e a educação no meio rural pode ser verificada no levantamento realizado junto às principais revistas científicas na área das Ciências da Educação editadas por instituições acadêmicas portuguesas, disponíveis em formato digital ou impresso. Nele foi possível encontrar 2.186 artigos, dos quais apenas 28 apresentam uma discussão relacionando mais diretamente à educação/escola e a realidade do mundo rural português, o que equivale a $1,28 \%$ de todas os artigos publicados em mais de uma década e meia (tabela 2).

A maioria dos textos discute a educação/escola do meio rural tendo o desenvolvimento local como pano de fundo. Autores como Amiguinho (2003b, 2005) e Canário $(2000,2003)$, além de textos que relatam experiências em projetos educativos de intervenção em nível local, escrevem sobre a escola rural como objeto de pesquisa. A concentração de artigos no campo do desenvolvimento local pode ser explicada pelo fato de que, dos 28 textos voltados à escola rural em Portugal, 11 compõem uma única publicação: o número 28 da revista Aprender, onde a grande maioria dos artigos discute experiências realizadas por projetos do ICE. Cabe destacar que, no período investigado, a Aprender foi a única revista científica que publicou um número cujo tema central foi a escola rural. 


\begin{tabular}{|c|c|c|c|c|}
\hline Revista & $\begin{array}{l}\text { Volumes } \\
\text { consultados }\end{array}$ & Responsável pela edição & $\begin{array}{c}\text { Artigos } \\
\text { publicados }\end{array}$ & $\begin{array}{c}\text { Artigos } \\
\text { sobre a } \\
\text { área }\end{array}$ \\
\hline $\begin{array}{l}\text { Revista Portuguesa } \\
\text { de Educação }\end{array}$ & $\begin{array}{l}\text { v. } 12 \text {, n. } 1 \text {, de } 1999 \text {, a } \\
\text { v. } 27 \text {, n. } 2 \text {, de } 2014\end{array}$ & $\begin{array}{lcc}\text { Universidade } & \text { do Minho } & - \\
\text { Centro de } & \text { Investigação em } \\
\text { Educação/ } & \text { Instituto } & \text { de } \\
\text { Educação } & & \\
\end{array}$ & 254 & 1 \\
\hline $\begin{array}{l}\text { Revista Lusófona } \\
\text { de Educação }\end{array}$ & $\begin{array}{l}\text { n. } 1 \text {, de } 2003 \text {, a n. } 28 \text {, } \\
\text { de } 2014\end{array}$ & Universidade Lusófona & 253 & 1 \\
\hline $\begin{array}{l}\text { Revista Portuguesa } \\
\text { de Pedagogia }\end{array}$ & $\begin{array}{l}\text { ano } 33, \text { n. } 1 \text {, de } 1999, \\
\text { a ano } 47, \text { n. } 2 \text {, de } \\
2013\end{array}$ & $\begin{array}{l}\text { Universidade de Coimbra - } \\
\text { Faculdade de Psicologia e } \\
\text { Ciências da Educação }\end{array}$ & 438 & 0 \\
\hline $\begin{array}{l}\text { Educação, } \\
\text { Sociedade \& } \\
\text { Culturas }\end{array}$ & $\begin{array}{l}\text { n. } 11 \text {, de } 1999 \text {, a } n . \\
43 \text {, de } 2014\end{array}$ & $\begin{array}{l}\text { Universidade do Porto - } \\
\text { Centro de Investigação e } \\
\text { Intervenção } \\
\text { Faculdade de Pducativas/ } \\
\text { Ciências da Educação }\end{array}$ & 259 & 5 \\
\hline $\begin{array}{l}\text { Revista Portuguesa } \\
\text { de Investigação } \\
\text { Educacional }\end{array}$ & $\begin{array}{l}\text { n. } 1 \text {, de } 2002 \text {, a n. } 14 \text {, } \\
\text { de } 2014\end{array}$ & $\begin{array}{l}\text { Universidade } \quad \text { Católica } \\
\text { Portuguesa }\end{array}$ & 115 & 1 \\
\hline Revista Interacções & $\begin{array}{l}\text { v. } 1 \text {, n. } 1 \text {, de } 2005 \text {, a } \\
\text { v. } 10 \text {, n. } 33 \text {, de } 2014\end{array}$ & $\begin{array}{l}\text { Escola Superior de Educação } \\
\text { de Santarém }\end{array}$ & 339 & 2 \\
\hline Revista Aprender & $\begin{array}{l}\text { n. } 22 \text {, de jul/99, a n. } \\
34 \text {, de out } / 2013\end{array}$ & $\begin{array}{l}\text { Escola Superior de Educação } \\
\text { de Portalegre }\end{array}$ & 188 & 16 \\
\hline Revista Sísifo & $\begin{array}{l}\text { n. } 1 \text {, de set/dez } 2006 \text {, } \\
\text { a n. 10, de set/dez } \\
2009\end{array}$ & $\begin{array}{l}\text { Universidade de Lisboa - } \\
\text { Unidade de I\&D de Ciências } \\
\text { da Educação }\end{array}$ & 116 & 2 \\
\hline $\begin{array}{l}\text { Revista de } \\
\text { Educação }\end{array}$ & $\begin{array}{l}\text { v. VIII, n. 1, de } 1999 \text {, } \\
\text { a v. XVIII, n. 2, de } \\
2011\end{array}$ & $\begin{array}{ll}\text { Universidade de Lisboa } & - \\
\text { Departamento } & \text { de } \\
\text { Educação/Faculdade } & \text { de } \\
\text { Ciências } & \end{array}$ & 183 & 0 \\
\hline \multirow[t]{2}{*}{$\begin{array}{l}\text { Sisyphus - Journal } \\
\text { of Education }\end{array}$} & $\begin{array}{l}\text { v.1, n. } 1-2013 \text {, a v. } 2 \text {, } \\
\text { n. } 3-2014\end{array}$ & $\begin{array}{l}\text { Universidade de Lisboa - } \\
\text { Instituto de Educação }\end{array}$ & 41 & 0 \\
\hline & & & 2186 & 28 \\
\hline
\end{tabular}

Tabela 2 - № de artigos voltados ao tema da educação/escola rural publicados em revistas científicas portuguesas concentradas na área das Ciências da Educação (1999 a 2014)

Os dados apresentados acima, mesmo não sendo suficientemente largos para abarcar o conjunto da produção acadêmica dos cursos de pósgraduação stricto sensu em funcionamento no país, ou mesmo de outros estudos realizados por investigadores das instituições de ensino superior, apontam a um visível distanciamento da academia em relação à problemática da educação rural, e sugerem que, embora existam importantes trabalhos publicados sobre o tema por autores de referência nas Ciências da Educação no país, a educação em meio rural ainda não constitui necessariamente uma 
área de investigação consolidada em Portugal (Sousa, 2008). Por outro lado, é possível que a frágil relação da academia com a problemática da educação dos habitantes do meio rural esteja ligada à excessiva orientação da pauta investigativa pela agenda política de cariz gestionário do Estado no setor educacional, o que, consequentemente, "faz da escola no mundo rural um tema periférico e marginal da actividade de investigação" (Canário, 2000, p. 122).

Nesse sentido, Canário (2000) argumenta que a abordagem sobre a problemática da escola rural em Portugal tem se mostrado duplamente reducionista, pois destaca o seu caráter interno ao sistema escolar e a coloca como questão meramente técnica, restringindo a problemática da escola rural a uma questão "de maior ou menor racionalidade da rede escolar, encarada numa perspectiva de 'eficácia', de 'qualidade' e de racionalização de custos" (Canário, 2000, pp. 127-128). Portanto, as escolas que não se enquadram no perfil considerado adequado pelo olhar tecnocrático, do Estado ou da academia, passam a ser negadas enquanto instituição capaz de oferecer os meios pedagógicos necessários a uma educação de qualidade e, portanto, deixam de existir como objeto de estudo.

Porém, alguns dos estudos que atravessaram a espessa zona cinzenta que esconde a escola rural do olhar acadêmico possibilitam perceber não só a relevância pedagógica, mas também a centralidade da escola para o desenvolvimento sustentado das comunidades rurais. Palmeiro (2011), por exemplo, assevera que o reordenamento do parque escolar que originou o encerramento da maioria das escolas do primeiro ciclo com reduzido número de alunos afetou mais profundamente as zonas rurais, que "viram desaparecer a única esperança de sobreviverem à desertificação a que estão votadas" (p. 5). Já Almeida (2007) argumenta que, por serem as pequenas escolas fundamentais na organização social da comunidade rural, o seu encerramento "implica mudanças drásticas no seio dos que lá vivem" (p. 140). Tal compreensão vai ao encontro do que pensa Canário (2006) ao referir-se à centralidade da escola nas dinâmicas socioeducativas desenvolvidas nas comunidades rurais, uma vez que, para ele, se por um lado o encerramento das escolas aligeira a morte das aldeias, por outro "a existência de escolas com projecto pode contribuir decisivamente para a revitalização social e cultural do mundo rural" (Canário, 2006, p. 235). 
No mesmo sentido, ao colocar em relevo a relação entre as autarquias e as escolas do meio rural, Palmeiro (2011) salienta que, diante da crise experimentada pelos territórios rurais, a escola, embora em progressiva degradação, se constitui no "último ícone" que, mais ou menos intacta, resiste ao longo do tempo. A autora ressalta ainda que as atividades realizadas pelas escolas rurais com as comunidades e as autarquias são fundamentais às pequenas localidades e seus habitantes, e que o encerramento de uma escola no meio rural "implica mais crianças deslocadas, maiores distâncias entre os locais de residência e a escola, maior distância relacional entre as famílias e a escola, o contributo para o despovoamento, envelhecimento, corte da relação inter-geracional e abandono dos lugares e aldeias rurais" (Palmeiro, 2011, p. 120).

Em estudo realizado no norte de Portugal, Silva (2010), reconhecendo que a "base sólida de qualquer processo sustentável de desenvolvimento é o conhecimento", nomeadamente aquele que "adquire-se ao longo da vida eruditamente a partir da educação, da escola e da formação", aponta como fundamental para a superação dos problemas ligados ao desenvolvimento no local estudado o enfrentamento das "baixas qualificações escolares dos mais jovens e profissionais da população activa". Portanto, para a autora, o estreitamento da ligação entre a rede escolar e o processo de desenvolvimento mostra-se fundamental ao alcance dos "objectivos da coesão sustentável, da intensificação tecnológica da base produtiva regional, da competitividade, qualificação/formação e inclusão social e territorial" (Silva, 2010, p. 185).

Apesar da crise em que se encontra, resultado das opções do modelo de desenvolvimento atualmente hegemônico, o meio rural português ainda é um espaço de produção de vida, onde milhões de pessoas vivem e trabalham, geram riqueza, constroem, remodelam e preservam cultura, ensinam e aprendem em instituições de ensino ou fora delas. A escola, grande ou pequena, agrupada ou isolada, com mais ou menos possibilidades materiais e pedagógicas, com suficiente qualificação docente ou não, de alguma forma influencia no desenvolvimento da comunidade rural. Diferentemente do que aponta a frágil ligação acadêmica à problemática da escola em meio rural, "é possível, interessante, útil e pertinente, do ponto de vista investigativo, exercer um olhar crítico sobre esse objecto social, em vias de extinção, e 
tentar transformá-lo num objecto de estudo" (Canário, 2000, p. 123). Entretanto, mais de quinze anos depois da constatação feita por Sarmento et al. (1998), percebe-se que embora a escola rural tenha deixado de ser um não-assunto, ela continua a ser um tema insuficientemente investigado.

\section{Considerações finais}

O olhar, ainda que estrangeiro, que minimamente atravesse a realidade educacional contemporânea em Portugal, destacando a produção acadêmica recente no campo das Ciências da Educação, não terá grande dificuldade em perceber a crescente invisibilidade da escola rural, seja na produção científica em nível da pós-graduação, nas publicações especializadas, ou mesmo na estrutura curricular dos cursos de licenciatura. Embora não seja uma exclusividade portuguesa, no país a academia, e mais especificamente o campo das Ciências da Educação, mesmo com resistências verificadas aqui e acolá, parece se render e endossar a premissa segundo a qual o progresso e o desenvolvimento encontram-se circunscritos exclusivamente ao meio urbano, sendo o espaço rural, inevitavelmente, um espaço identificado com o passado.

Tal fato, consequentemente, pode vir a refletir negativamente na formação dos novos docentes e pesquisadores, pois a escassez de estudos dificulta a introdução consistente da problemática em questão nos cursos de formação inicial de docentes e tende a dificultar uma compreensão mais alargada dos desafios e tensões existentes no campo educacional, especialmente no processo de formatação das políticas educativas.

Enxerga-se também a escassez de força social que, enraizada nos contextos locais e atrelada aos interesses dos sujeitos do meio rural, seja capaz de fazer a academia voltar o olhar à escola que atende a população e propor ações pedagógicas para além da formação profissional stricto sensu, onde prepondera o aspecto econômico, e avançar para um movimento educativo mais largo assente sobre os elementos identitários dos sujeitos do meio rural.

Nesse sentido, pode-se seguir e ampliar a trilha aberta por experiências de sucesso como o Projeto Escolas Rurais executado pelo ICE, que têm mostrado o potencial que as escolas rurais, mesmo as pequenas, 
demonstram no desenvolvimento de experiencias pedagógicas que se contrapõem ao modelo escolar hegemônico. Ao envolverem a comunidade em suas atividades, ao se abrirem para relacionamentos com modalidades educativas não escolares e ao servirem de catalisadoras do desenvolvimento local, as escolas se enraízam nas comunidades e ajudam a mobilizá-las para a definição de saídas endogenamente construídas aos seus desafios.

\section{Financiamento}

O estudo que viabilizou a construção deste artigo foi apoiado pela Coordenação de Aperfeiçoamento de Pessoal de Nível Superior - CAPES - através de uma bolsa de Pós-Doutorado - Proc. 6186/2014-09.

\section{Notas}

1 "Aglomerado populacional com 10 ou mais alojamentos destinados à habitação de pessoas e com designação própria independentemente de pertencer a uma ou mais freguesias. Os seus limites devem ter em atenção a continuidade de construção, ou seja, edifícios que não distem entre si mais de 200 metros" (INE, 2015).

2 Este texto atualiza e amplia dados que foram levantados anteriormente para fundamentar a discussão de um trecho da tese de doutoramento do autor, defendida em 2011 na Universidade do Minho.

3 O ICE é uma associação de âmbito nacional, de utilidade pública sem fins lucrativos, com o estatuto de ONG e sede em Setúbal. Tem como finalidades a organização, gestão, animação e apoio a projetos de intervenção, investigação e desenvolvimento, no âmbito educativo, cultural, social e económico.

4 Levantamento realizado no dia 15 de junho de 2015.

5 Levantamento realizado no dia 14 de junho de 2015.

\section{Referências}

Almeida, A. (2007). A educação em meios rurais e a multiculturalidade: $O$ encerramento dos pequenos estabelecimentos de ensino no meio rural - Um olhar crítico (Dissertação de Mestrado). Universidade Aberta, Porto.

Amiguinho, A. (1995). Um testemunho em torno da problemática e da intervenção na escola rural. In Conselho Nacional de Educação, Actas do Seminário "Educação e meios rurais: Problemas e caminhos do desenvolvimento" (pp. 110-132). Lisboa: CNE. 
Amiguinho, A. (2003a). A construção progressiva de um projecto de intervenção em meio rural. Escolas Rurais: De obstáculo a recursos (Região do Norte Alentejano). Aprender, 28, 96-102.

Amiguinho, A. (2003b). Educação e mundo rural: Percursos biográficos, intervenção e pesquisa. Educação, Sociedade \& Culturas, 20, 9-42.

Amiguinho, A. (2005). A escola e o futuro do mundo rural (Tese de Doutoramento). Universidade de Lisboa, Lisboa.

Amiguinho, A., Canário, R., \& D’Espiney, R. (1994). Escolas e processos de desenvolvimento local: O exemplo do projecto das escolas isoladas. In R. D’Espiney (Org.), Escolas isoladas em movimento (pp. 10-33). Setúbal: ICE.

Calvário, R. (2010). Política de desenvolvimento rural na União Europeia: Agricultura, ambiente e território (Dissertação de Mestrado). Faculdade de Ciências e Tecnologia, Universidade Nova de Lisboa, Lisboa.

Calvi, J. (1995). A escola, uma estrutura em osmose com o seu meio ambiente. In R. Canário (Org.), Escola rural na Europa (pp. 85-94). Setúbal: ICE.

Campos, B. (1995). A pesquisa educacional em Portugal. Disponível em: http://repositorio-aberto.up.pt/bitstream/10216/2075/5/A\%20investigacao\%20 educacional\%20em\%20Portugal.pdf

Canário, R. (1995). Nota de apresentação. In R. Canário (Org.), Escola rural na Europa (pp. 9-12). Setúbal: ICE.

Canário, R. (1997). Educação e perspectivas de desenvolvimento do "interior". Disponível em: http://jorgesampaio.arquivo.presidencia.pt/pt/biblioteca/outros/ interioridade/1_3.html

Canário, R. (2000). A escola no mundo rural: Contributo para a construção de um objecto de estudo. Educação, Sociedade \& Culturas, 14, 121-139.

Canário, R. (2003). Escola rural: Pensar o educativo, o social e o político. Aprender, 28, 96-102.

Canário, R. (2006). Aprender sem ser ensinado. A importância estratégica da educação não formal. In L. Lima, J. A. Pacheco, M. Esteves, \& R. Canário, A educação em Portugal (1986-2006): Alguns contributos de investigação. Lisboa: Sociedade Portuguesa de Ciências da Educação. Disponível em: http://www.adcl.org.pt/ observatorio/pdf/AeducacaoemPortugal_1986_2006.pdf

Collot, B. (1994). Escola rural: Uma opção. In R. D’Espiney (Org.), Escolas isoladas em movimento (pp. 61-79). Setúbal: ICE.

Correia, J., \& Stoer, S. (1995). Investigação em educação em Portugal: Esboço de uma análise crítica. Disponível em: http://repositorio-aberto.up.pt/bitstream/ 10216/13683/2/Investigao\%20em\%20educao\%20em\%20Portugal\%20esboo\% 20de\%20uma\%20anlise\%20crtica.pdf

Covas, A., \& Covas, M. (2013). A caminho da $2^{a}$ ruralidade: A microgeoeconomia de novos sistemas territoriais - A experiência do Projecto Querença. In J. R. Fernandes, L. Cunha, \& P. Chamusca (Orgs.), Geografia \& Política, políticas e planeamento (pp. 528-540). Porto: FLUP/CEGOT.

Formosinho, J. (1998). Educação para todos. O ensino primário: De ciclo único do ensino básico a ciclo intermédio da educação básica. Cadernos PEPT 2000, 21. Lisboa: Ministério da Educação. 
Instituto Nacional de Estatística - INE (2015). Conceito de lugar. Disponível em: http://smi.ine.pt/ Conceito/Detalhes/2990

Iturra, R. (1990). Fugirás à escola para trabalhar a terra: Ensaios de antropologia social sobre o insucesso escolar. Lisboa: Escher.

Melo, A. (1994). Educação e formação para o desenvolvimento rural. In L. Lima (Org.), Educação de adultos - Fórum I (pp. 137-149). Braga: Universidade do Minho.

Nascimento, P. (2008). Políticas de desenvolvimento e educação em contexto rural (1986-2004). Escolaridade básica e dinâmicas sociais no Vale do Cávado (Amares, Terras de Bouro e Vila Verde) (Tese de Doutoramento). IEC/Universidade do Minho, Braga.

Oliveira, J. (2005). A educação em meio rural como paleta de possibilidades para o desenvolvimento local: Contributos da escola do $1^{\circ}$ ciclo do ensino básico e do jardim de infância (Tese de Doutoramento). IEC/Universidade do Minho, Braga.

Palmeiro, A. (2011). Autarquias e escolas no meio rural (Dissertação de Mestrado). Instituto Politécnico de Portalegre, Escola Superior de Educação, Portalegre.

Pinto, J. M. (1985). Estruturas sociais e práticas simbólico-ideológicas nos campos. Elementos de teoria e de pesquisa empírica. Porto: Edições Afrontamento.

Ministério da Agricultura e do Mar (2014). Programa de desenvolvimento rural do Continente 2014-2020. Lisboa: Ministério da Agricultura e do Mar, Gabinete de Planeamento e Políticas.

Sarmento, M., \& Oliveira, J. (2005). A escola é o melhor do povo: Relatório de revisão institucional do projecto das escolas rurais. Porto: Profedições.

Sarmento, M., Sousa, T., \& Ferreira, F. (1998). Tradição e mudança na escola rural: Estudo de caso. Lisboa: Ministério da Educação.

Silva, A. (2010). Coalescência e excentricidade da NUT III Tâmega. As novas dinâmicas de desenvolvimento do mundo rural: Aposta na governança escolar democrática. Cadernos de Doutoramento em Geografia, 10, 163-187.

Silva, A., \& Marques, H. (2013). A procura do rural tradicional: Retratos de desenvolvimento. In J. R. Fernandes, L. Cunha, \& P. Chamusca (Orgs.), Geografia \& Política, políticas e planeamento (pp. 516-528). Porto: FLUP/CEGOT.

Sousa, F. (2008). A diferenciação como princípio de organização curricular. In E. Shiroma \& P. Torriglia (Orgs.), Atas do IV Colóquio Luso-Brasileiro sobre Questões Curriculares/VIII Colóquio sobre Questões Curriculares. Florianópolis: Universidade Federal de Santa Catarina.

Souza, F. (2011). Os colégios rurais agrupados na Espanha: Espaços de fortalecimento do campesinato? Revista NERA, 14(18), 21-36.

Stoer, S., \& Araújo, H. (1992). A escola e a aprendizagem para o trabalho num país da (semi)periferia europeia. Lisboa: Escher.

Vendramini, C. (2005). Movimentos educativos emancipatórios em Portugal. Disponível em: http://www.anped.org.br/ reunioes/28/inicio.htm

Yves, J. (1995). Estado, escola e crise dos espaços rurais. In R. Canário (Org.), Escola rural na Europa (pp. 33-47). Setúbal: ICE. 
THE RURAL SCHOOL IN THE PORTUGUESE ACADEMIC PRODUCTION: NOTES ON THE (IN)VISIBILITY OF AN OBJECT OF STUDY

\begin{abstract}
This paper discusses the invisibility of rural school in the Portuguese university. Although there is scientific production focused on rural and their sociocultural relations, which focuses, directly or indirectly, on the school, from the 1980s, with Pinto (1985), through Stoer and Araújo (1992) and Canário (1995), until the end of the 1990s, with Sarmento, Sousa, and Ferreira (1998), the academic output does not fully discuss the rural school. It has not been up to the social, cultural and economic importance of that space. The research occurs through a bibliographic study in ten scientific journals on education, and the survey of theses and dissertations produced in the main Portuguese universities. The data suggest a growing invisibility of the rural school in the academic literature and in specialized publications on education in Portugal, and the absence of a social force linked to the interests of the subjects of the countryside able to reinstate the interest of the university in the rural school.
\end{abstract}

Keywords

Rural school; Invisibility; Academic production

\title{
L'ÉCOLE RURALE DANS LA PRODUCTION ACADÉMIQUE PORTUGAISE : REMARQUES SUR LA (IN)VISIBILITÉ D'UN OBJET D'ÉTUDE
}

\section{Résumé}

Cet article traite de l'invisibilité de l'école rurale à l'université portugaise. Bien qu'il y ait production scientifique axée sur rurale et leurs relations socioculturelles, qui se concentre, directement ou indirectement, sur l'école, des années 1980, avec Pinto (1985), à travers Stoer et Araújo (1992) et des Canário (1995), jusqu'à ce que atteindre la fin des années 1990, avec Sarmento, Sousa, et Ferreira (1998), la production universitaire sûr l'école 
rurale n'était prêt à discuter l'importance sociale, culturelle et économique de cet espace. La recherche se fait par une étude bibliographique dans dix revues scientifiques dirigées à l'éducation, et l'enquête de thèses et mémoires produits dans les principales universités portugaises. Les données suggèrent une invisibilité croissante de l'école rurale dans la littérature académique et dans des publications spécialisées sur l'éducation au Portugal, et l'absence de force sociale liée aux intérêts des sujets de la campagne capables de retourner l'université à l'école rurale.

Mots-clé

École rurale; Invisibilité; Production académique

Recebido em dezembro/2015 Aceite para publicação em julho/2016

i Faculdade de Pedagogia, Universidade Federal do Pará - UFPA, Brasil.

Toda a correspondência relativa a este artigo deve ser enviada para: Carlos Renilton Freitas Cruz, Faculdade de Pedagogia do Campus Castanhal/UFPA, Av. dos Universitários, s/n - Jaderlândia, Castanhal - PA, 68746-630, Brasil. E-mail: renilton@ufpa.br 